\title{
A FORMAÇÃO CONTINUADA PARA PROFESSORES DA EDUCAÇÃO DO CAMPO'
}

\author{
CONTINUING TRAINING FOR FIELD TEACHERS
}

\author{
Heliene Pimentel de Sousa² e Eliane Aparecida Galvão dos Santos ${ }^{3}$
}

\section{RESUMO}

O presente trabalho trata de um recorte de uma pesquisa de mestrado realizada em uma universidade do interior do RS, a qual analisa como acontece a formação continuada dos docentes da educação infantil nas escolas do campo. Assim, o objetivo deste é refletir sobre a formação continuada de professores da educação infantil do campo por meio de uma discussão teórico-conceitual a luz de referenciais teóricos e dos marcos regulatórios desta categoria de educacional. Para a pesquisa se fez uma pesquisa bibliográfica de abordagem qualitativa descritiva. Como resultados evidencia-se que a qualificação profissional, nas escolas do campo de educação infantil, ainda é uma realidade que está em processo de construção, pois ainda existem professores sem a adequada formação profissional para trabalhar com a educação infantil no campo. Portanto, a formação continuada para os professores que atuam no campo deve contemplar as especificidades dessa modalidade de ensino, e para tanto é imprescindível o investimento de políticas públicas voltadas as necessidades desses territórios.

Palavras-chave: Educação no Campo, Educação infantil, Formação Docente.

\section{ABSTRACT}

This article is an excerpt from a master's research carried out at a university in the interior of RS, which analyzes how the continuing education of early childhood teachers in rural schools takes place. In this work, the objective is to reflect on the continuing education of teachers of early childhood education in the field through a theoretical-conceptual discussion in the light of theoretical references and regulatory frameworks for early childhood education. This is a qualitative, descriptive research. As a result, it is evident that professional qualification in schools in the field of early childhood education is still a reality that is in the process of being built, as there are still teachers without adequate professional training to work with early childhood education in the field. Therefore, continuing education for teachers who work in the field must take into account the specificities of this teaching modality, and for that, it is essential to invest in public policies aimed at the needs of these territories.

Keywords: Rural Education, Early Childhood Education, Teacher Education.

1 Artigo de pesquisa do mestrado.

2 Mestra, Mestrado em Ensino de Humanidades e Linguagens. E-mail: helieneufpa@hotmail.com

3 Orientadora - Licenciada em Pedagogia. Mestre e doutora em Educação pela Universidade Federal de Santa Maria. Coordenadora do Curso de Pedagogia da Universidade Franciscana (UFN) e professora adjunta do mestrado em Ensino de Humanidades e Linguagens (UFN). E-mail: elianeagalvao1@gmail.com 


\section{INTRODUÇÃO}

Aprender a ser professor é um processo complexo, pois envolve a formação de seres humanos em processo de desenvolvimento afetivo, cognitivo e intelectual, além de que, a profissão docente compreende várias dimensões como avaliação, planejamento, didática, entre outros, e exige uma formação contínua. Entende-se a formação de professores como um processo contínuo que é construído durante toda a vida que não se restringe apenas ao nível médio de magistério, nível superior ou cursos de especializações.

Embora seja um tema recorrente nas políticas públicas educacionais e no chão das escolas, ainda é atual a presença de um alto índice de professores, sem a devida formação, que atuam na educação infantil em regiões como o norte e nordeste do Estado do Pará e com destaque ao tocante à modalidade da educação do campo. Assim, é como se este contexto não estivesse inserido nas políticas públicas educacionais. Segundo dados do IBGE 2016, 0,3\% dos professores atuam na pré-escola apenas com o ensino fundamental e $0,5 \%$ em creches, também com apenas com o ensino fundamental e, ainda aparece $0,1 \%$ com ensino fundamental incompleto tanto na creche como na pré-escola.

É preciso valorizar o profissional que atua no campo, em especial o que atua na educação infantil, pois como pesquisadora e como profissional desse contexto, a realidade vivenciada tem mostrado que para essa etapa qualquer um pode atuar, mesmo sem as exigências mínimas que a Lei de Diretrizes e Bases da Educação Nacional de 1996 (LDB) exige. Porém, é cada vez mais preciso que o profissional da educação possa estar se qualificando e buscando a formação contínua, para assim, melhorar suas práticas frente aos reais problemas do contexto educacional e das demandas da escola.

Pensar na educação infantil do campo requer um olhar especial a que "tipo de educador" está se formando para atuar com esses alunos. Não é fácil trabalhar na educação infantil, pois são os alunos que estão em processo de desenvolvimento e precisam ser olhados em sua globalidade como seres que têm referências específicas do campo e que precisam ser respeitadas. Não se pode mais copiar a educação urbana e levar para o campo. Diante desse contexto, é preciso aprofundar estudos sobre o tema e assim conhecer melhor as realidades relativas à educação infantil na modalidade da educação do campo.

O objetivo deste trabalho é refletir sobre a formação continuada de professores da educação infantil do campo por meio de uma discussão teórico-conceitual a luz de referenciais teóricos e dos marcos regulatórios desta categoria de educacional. O presente trabalho trata de uma revisão de literatura realizada durante o mestrado, que faz parte da dissertação final.

\section{FORMAÇÃO CONTINUADA PARA PROFESSORES DA EDUCAÇÃO DO CAMPO}

As pesquisas sobre a educação do campo e, em especial a educação infantil, ficaram silenciadas nas pesquisas sociais e educacionais, dados estes que são preocupantes. É como se os sujeitos do 
campo não existissem, e seus direitos por uma educação de qualidade no e do campo são negados, segundo Arroyo, Caldart e Molina (2009).

Por que a educação da população do campo foi esquecida? Um dado que exige explicação: somente $2 \%$ das pesquisas dizem respeito a questões do campo, não chegando a $1 \%$ as que tratam especificamente da educação escolar no meio rural (ARROYO; CALDART; MOLINA; 2009, p. 8)

Para se pensar em uma educação para os sujeitos do campo, deve-se levar em consideração o currículo, avaliação e organização pedagógica que contemple a realidade da vida do homem do campo para que assim tenham condições de modificar sua própria realidade enquanto excluídos, sem precisarem sair para a zona urbana em busca de melhores condições de vida.

A escola do campo deve ser inclusiva, democrática, igualitária, que trate com respeito e dignidade as crianças, jovens e adultos do campo, que não aumente a exclusão dos que já são tão excluídos. Tarefa urgentíssima para a construção da educação básica do campo: criar estruturas escolares inclusivas (ARROYO, 2004, p. 86).

A Lei de Diretrizes e Bases da Educação Nacional - LDB (BRASIL, 1996) deixa claro que todos têm direitos e deveres que devem ser respeitados. Porém, na maioria das vezes não é isso que acontece, principalmente com relação à qualificação do profissional da educação infantil que quando entra no mérito da educação do campo encontra uma realidade complexa, as leis existem, porém, não são cumpridas e respeitadas (BRASIL, 1996). Ainda nesta lei, no Art. $62^{\circ}$ refere-se à formação exigida do professor para atuar na Educação Básica, em que:

far-se-á em nível superior, em curso de licenciatura, de graduação plena, em universidades e institutos superiores de educação, admitida, como formação mínima para o exercício do magistério na educação infantil e nas quatro primeiras séries do ensino fundamental, a oferecida em nível médio, na modalidade Normal. (BRASIL, 1996, p. 25).

Um dos grandes desafios da educação infantil de qualidade é a formação de um profissional que procure o saber enquanto pesquisador de sua própria prática e que saiba dialogar com os profissionais especializados das diversas áreas. A Constituição Federal Brasileira (BRASIL, 1988) e a LDB (BRASIL, 1996) vêm dar um novo rumo para as creches e pré-escolas, antes dessa legalidade, as creches em sua maioria estavam na responsabilidade de órgãos não educacionais especialmente na área de bem-estar social. Já, as pré-escolas mesmo fazendo parte do sistema de ensino, precisavam de uma legislação mais clara, pois a Lei Reforma do Ensino de $1^{\circ}$ e $2^{\circ}$ graus n. ${ }^{\circ} 5.692 / 1971$, apenas dizia que os sistemas de ensino deveriam "zelar" pelas crianças menores de sete anos, idade em que se inicia o período de escolaridade obrigatória (BRASIL, 1971).

Para educar a criança, entende-se a formação inicial como apenas um dos momentos do processo formativo, questionando que a formação inicial sozinha não é suficiente, pois é necessário um 
conjunto de fatores, entre eles a formação continuada como uma das partes desse processo de formação de professores no qual Mizukami (2002) explica:

A ideia de processo - e, portanto, contínua - obriga a considerar a necessidade de estabelecimento de um fio condutor que vá produzindo os sentidos e explicando os significados ao longo de toda a vida do professor, garantindo ao mesmo tempo, os nexos entre formação inicial, a continuada e as experiências vividas (MIZUKAMI, 2002, p. 16).

Existe a necessidade de entender o processo de formação como fio condutor que não acontece somente no ensino superior, nem tão pouco com a prática docente, mas sim como um conjunto de processos que são indispensáveis. Segundo Guimarães (2012), muitas pesquisas apontam para a necessidade de criação de políticas públicas que atendam às expectativas dos professores tanto no campo como na cidade. Dentre as dificuldades para melhorar a educação do campo, destaca-se a formação dos professores.

Entende-se que a tarefa de educar sempre foi complexa, porém nas últimas décadas, essa complexidade aumentou bem mais, a formação deve trabalhar a partir do pensamento complexo, deixar de lado o pensamento uniforme e simplista, para assim trazer reflexões e tomada de decisões adequadas. Uma mudança na formação do professor não é simples, pois estamos falando em mudanças que geram transformações, e elas nem sempre são olhadas como necessárias.

Um dos mitos na profissão docente é que "ensinar é fácil". No entanto, ensinar sempre foi difícil, e cada dia essa dificuldade vem aumentando, sendo até arriscada em alguns lugares. Os avanços da ciência, da psicopedagogia, das estruturas sociais, a influência dos meios de comunicação de massa e os novos valores, entre uma base de incertezas e mudanças, já que a formação, até agora, não se ocupou disso. São velhos e novos desafios que continuam fazendo que a educação seja difícil e, nos novos tempos, mais complexa. A complexidade aumentou em decorrência do contexto. Quando falamos de contexto, estávamos nos referindo tanto a lugares concretos, instituições educacionais, quanto a fatores que caracterizam os ambientes sociais e de trabalho (IMBERNÓN, 2010. p. 100).

Conforme citado, Imbernón (2010) afirma que ser professor no contexto atual não é fácil, e em alguns momentos chega a ser perigoso. Educar é difícil, pois envolve seres humanos, cada um com sua especificidade e complexidade as quais devem ser levadas em consideração pelo professor. Por isso, trabalhar a formação continuada não é simples, pois deve proporcionar subsídios para que o professor tenha condições necessárias de enfrentar essas complexidades da vida profissional.

$\mathrm{Na}$ formação continuada diversos fatores têm influência, tais como: a formação inicial adquirida, a cultura, a gestão escolar, a comunidade escolar e a complexidade das instituições de ensino. $\mathrm{O}$ ato de educar sempre foi complexo, por ser uma ação social que envolve indivíduos com características próprias, pois dentro de uma sala de aula, faz-se necessário a tomada de atitudes rápidas para responder às demandas diárias. Saber reconhecer a complexidade na prática docente significa compreender que promover uma formação que possibilite reflexões acerca da problemática, pode 
fazer com que os professores melhorem em suas práticas pedagógicas com reflexões aprofundadas de como melhorar sua atuação.

Reconhecer a complexidade do pensamento e da prática docente significa aceitar que a educação, como fenômeno social, é uma rede aberta; que essa abertura faz com que, às vezes, se tomem decisões sem reflexão prévia, de forma intuitiva; que promover uma formação que facilita a reflexão e a intuição pode fazer com que os professores sejam melhores planejadores e gestores do ensino-aprendizagem e, por que não, agentes sociais, que podem da estrutura social e laboral. Mas o que é complexo na profissão docente? (IMBERNÓN, 2010. p. 101).

Segundo Morin (2000), por complexidade entende-se as inquietações daquilo que está emaranhado, confuso, desordenado, incerto como a mistura de ordem/desordem/interação/organização com a dissolução desses elementos. Isso nos leva a navegar por um ensino das certezas e incertezas, a enfrentar o risco, o inesperado, o incerto. O autor também considera "Em consequência, a educação deve promover a "inteligência geral" apta a referir-se ao complexo, ao contexto, de modo multidimensional e dentro da concepção global” (p. 39).

A formação significa não buscar respostas, mas, sim ver os novos desafios, desafios esses que levam a uma mente aberta a novas possibilidades, Morin diz que a educação deve dar possibilidades de "preparar as mentes para responder aos desafios que a crescente complexidade dos problemas impõe ao conhecimento humano; - preparar as mentes para enfrentar as incertezas que não param de aumentar" (MORIN, 2003, p. 102). Nesse sentido, o autor reforça que o pensamento simples resolve problemas simples, que o dialógico na formação dos professores nos leva a analisar diversos caminhos que nos fazem pensar o contexto da realidade educacional. De acordo com Imbernon (2010, p. 102) “O princípio dialógico está presente na relação conflito-harmonia com o contexto, ou seja, na formação em que se concebe o professor, seja como educador seja como instrutor”. Mas o dialógico não é desordem, mas, sim fomento da criatividade mais além dos recursos técnicos. Assim, o dialógico nos leva à compreensão da contradição da realidade educacional e profissional. Deve-se levar em conta o respeito à diferença a partir da diversidade.

Ao nos situarmos no paradigma da complexidade, estamos propondo uma nova forma de pensar e repensar a educação. A formação deve propor um processo que capacite os professores para aprender a aprender, mas, também, para aprenderem a desaprender com comunicação, autoanálise e regulação própria, mediante conhecimentos e habilidades e atitudes, a fim de desenvolver profissionais inquietos e inovadores; que aprendam com seus acertos e erros. Para conseguir isso é fundamental o desenvolvimento de instrumentos intelectuais que facilitem as capacidades reflexivas sobre a própria prática docente e cuja principal meta seja aprender a interpretar, compreender e refletir sobre o ensino e a realidade social de forma comunitária. A criação de redes de questionamentos a pesquisa e o desenvolvimento do pensamento crítico nos ajudarão a compreender a complexidade (Imbernón, 2010, p. 104).

O grande desafio do professor é aprender a aprender na atualidade, saber refletir sobre sua realidade e contexto educacional, trocar experiência com os colegas de trabalho, e ser um pesquisador de 
sua própria prática, trocando experiências pedagógicas.A formação de professores é vista como um dos mais importantes fatores para a melhoria de padrões de qualidade na Educação em qualquer nível ou modalidade e ensino. No Brasil, a relevância da questão tem levado vários estudiosos e profissionais que atuam na área a promover discussões e elaborar propostas para a formação do profissional de educação infantil, especialmente daqueles que trabalham em creches (ROSEMBERG, 1992).

A educação infantil deve cumprir dois importantes papéis: o cuidar e o educar, complementando os cuidados e a educação realizados na família. Sendo assim o professor que atua na creche e pré-escola deve ser reconhecido como profissional sendo lhe garantindo condições de trabalho, plano de carreira, salário e formação continuada condizentes com o papel que desempenha. A educação infantil, que abrange o atendimento a alunos de zero a cinco anos em creches e pré-escolas, exigindo que o professor cumpra as funções de cuidar e educar, o desafio da qualidade se apresenta com uma dimensão maior, pois é sabido que os mecanismos atuais de formação não contemplam esta dupla função, é preciso, portanto, que formas regulares de formação e especialização, bem como mecanismos de atualização dos profissionais sejam assegurados e que esta formação seja orientada pelos pressupostos e diretrizes expressos na Política de Educação Infantil.

\begin{abstract}
as crianças são cidadãs, ou seja, são indivíduos sociais que têm direitos a que o Estado deve atender, dentre eles o direito à educação, saúde, seguridade. Esses serviços devem ser de qualidade, se o projeto político é de fato - democrático. Esse pressuposto afirma, pois, o direito à igualdade e ao real exercício da cidadania [..\}.. Só é possível concretizar um trabalho com a infância, voltado para a construção da cidadania e a emancipação [...], se os adultos envolvidos forem dessa forma considerados. Isso implica no entendimento de que os mecanismos de formação sejam percebidos como prática social inevitavelmente coerente com a prática que se pretende implantar na sala de aula e implica em salários, planos de carreira e condições de trabalho dignas. (SOUZA; KRAMER, 1993, p. 54-55).
\end{abstract}

A garantia da Educação dos alunos de 0 a 5 anos exige condições que viabilizem a produção do conhecimento, implantação e avaliação de múltiplas estratégias curriculares para creches e pré-escolas e para a formação inicial e em serviço de seus professores e dos profissionais como um todo da escola. Uma política de formação do professor deve levar em consideração as singularidade e subjetividades do aluno, seus processos formativos e todo o processo de formação global do aluno. Uma Política de formação de professores deve ser entrelaçada na emancipação e na construção da cidadania, precisam, sobretudo, garantir as condições para que as práticas desenvolvidas sejam entendidas como práticas sociais, e seus atores (professor e aluno) sejam percebidos como sujeitos autores dessa prática.

Os professores precisam de tempo e motivação para os estudos de sua própria prática. As políticas de formação de professores precisam assegurar tempo de acesso a bibliotecas e a grupos de estudos no interior do local de trabalho, como parte de seu trabalho. E só farão quando tiverem a compreensão que esse tipo de formação ultrapassa os limites da sala de aula e as modalidades de formação convencional. 
Atualmente, no Brasil, segundo o Instituto Nacional de Estudos e Pesquisa Educacionais Anísio Teixeira (INEP), o número de professores é de 2,5 milhões. Esse número muito elevando de professores representa uma ideia da magnitude e importância da formação de professores nas políticas educacionais. Segundo Akkari (2011) “Em todos os países o sistema educacional é o maior empregador. Os professores constituem a classe de trabalhadores numericamente mais importante" (p. 108). Esses dados demonstram a necessidade e complexidade de formulações de políticas educacionais para um número tão elevado de professores.

A formação de professores deve ser entendida como imprescindível nos dias atuais e como um processo contínuo que dura por toda a carreira profissional. "A formação pode, também ser entendida como um processo de desenvolvimento e estruturação da pessoa que se realiza com o duplo efeito de maturação interna e de possibilidades de aprendizagem, de experiências dos sujeitos" (GARCIA, 1999, p. 19). Dentro do processo formativo o autor referenda três conceitos: a auto formação, heteroformação e interformação.

\footnotetext{
A auto formação é uma formação em que o indivíduo participa de forma independente e tendo sob seu próprio controlo os objetivos, os processos, os instrumentos e os resultados da própria formação. A heteroformação é uma formação que se organiza e desenvolve "a partir de fora", por especialistas, sem que seja comprometida a personalidade do sujeito que participa. Por último a interformação define-se como "a ação educativa que ocorre entre os futuros professores ou entre professores em fase de actualização de conhecimento... e que existe como um apoio privilegiado no trabalho da equipe pedagógica, tal como hoje é concebido como formação do amanhã" (GARCIA, 1999, p. 20).
}

Entende-se a formação de professores não como um treino, mas como um processo reflexivo e de atuação. Imbernón (2005) destaca cinco grandes eixos de atuação:

A primeira seria reflexão sobre sua própria prática, mediante reflexão da sua realidade e intervenção sobre ela, tornando o professor capaz de gerar conhecimento por meio da sua prática pedagógica;

A segunda seria troca de experiência entre educadores, aumentando a comunicação entre os professores; A terceira, a união da formação a um projeto de trabalho; A quarta, a formação como estímulo crítico; A quinta, o desenvolvimento profissional da instituição com objetivo de transformar a prática, transpassando da prática inovadora individual para prática inovadora institucional.

A formação deve ter como base a formação reflexiva dos sujeitos sobre sua prática docente, permitindo refletir sobre atitudes, conceitos e funcionamento de suas práticas, assim se propondo a realizar constante autoavaliação. A formação deve partir do princípio de que o professor é construtor de conhecimento pedagógico individual e coletivo. A experiência isolada pode até resultar em trabalhos inovadores, mas não levará a uma inovação coletiva da instituição e da prática coletiva dos profissionais. Segundo Imbernón (2005) "uma formação deve propor um processo que confira ao docente, conhecimentos, habilidade e atitudes para criar profissionais reflexivos ou investigadores" (p. 55). 
Historicamente, os processos formativos eram realizados para resolver problemas genéricos, padronizados, fora de contexto. Para diferentes contextos era oferecida a mesma solução sem levar em conta a situação geográfica, o contexto da realidade. A formação não deve ser um treinamento, e diante dessa realidade Imbernón diz que:

O tratamento da formação como um problema genérico ocasiona um sistema de formação standard, baseado em um modelo de treinamento. Muitos professores estão acostumados assistir cursos e seminários em que o palestrante é o especialista que estabelece o conteúdo e desenvolvimento das atividades. Em um curso ou em uma "sessão de treinamento", objetivos e os resultados esperados são claramente especificados e costumam a ser definidos em termos de conhecimento[...]. (IMBERNÓN, 2010, p. 54).

O Plano Nacional de Educação pela lei n. ${ }^{\circ}$ 13.005/2014 vêm trazendo metas para formação de professores de acordo com a meta 15.

Garantir, em regime de colaboração entre a União, os Estados, o Distrito Federal e os Municípios, no prazo de 1 (um) ano de vigência deste PNE, política nacional de formação dos profissionais da educação de que tratam os incisos I, II e III do caput do art. 61 da Lei n 9.394, de 20 de dezembro de 1996, assegurado que todos os professores e as professoras da educação básica possuam formação específica de nível superior, obtida em curso de licenciatura na área de conhecimento em que atuam. (BRASIL, 2014)

De acordo, com o Plano Nacional de Educação em regime de colaboração com a união, os Estados, o Distrito Federal e os municípios irão assegurar formação em nível superior para todos os professores em cursos de licenciatura. Porém, a LDB ainda assegura como requisito mínimo de formação para educação infantil e anos iniciais do ensino fundamental a formação em ensino médio na modalidade normal. A LDB referenda o seguinte: Art. $62^{\circ}$. A formação de docentes para atuar na educação básica far-se-á em nível superior, em curso de licenciatura plena, admitida, como formação mínima para o exercício do magistério na educação infantil e nos cinco primeiros anos do ensino fundamental, a oferecida em nível médio, na modalidade normal.

Para a formação continuada o documento do Plano Nacional de Educação (PNE) traz o seguinte: Formar, em nível de pós-graduação $50 \%$ dos professores da educação básica, até o último ano de vigência deste PNE, e garantir a todos (as) os (as) profissionais da educação básica formação continuada em sua área de atuação, considerando as necessidades, demandas e contextualizações dos sistemas de ensino. Essa demanda vem afirmando a necessidade e importância da formação continuada para todos os educadores. O plano nacional vem tentando valorizar o profissional da educação, bem como a melhoria da educação de modo geral. Essa tentativa de melhorar a educação por meio de formação continuada vai depender também da cooperação dos entes federativos. 
Essa valorização dos profissionais da educação faz-se necessária por parte dos entes federativos, por entender-se que a formação de professores é o passo primordial para a elevação e melhoria da qualidade da Educação com um todo.

A Base Nacional Comum Curricular (BNCC) traz novos pontos para atuação profissional do professor, "O principal objetivo é orientar uma linguagem comum sobre o que se espera da formação de professores, a fim de revisar as diretrizes dos cursos de pedagogia e das licenciaturas para que tenham foco na prática da sala de aula e estejam alinhadas à BNCC. O texto destaca que formação inicial e continuada deve seguir três dimensões: conhecimento teórico, prática e engajamento. A dimensão conhecimento tem relação com domínio dos conteúdos. A prática tem relação com o saber desenvolver ambientes de aprendizagem. A terceira dimensão o engajamento tem relação com o compromisso do professor com a aprendizagem, a interação e a comunicação com os colegas de trabalhos, a família e comunidade escolar.

Diante dessa proposta, ao profissional da educação, deve-se oferecer possibilidades e formação continuada para lhe ajudar a assegurar essas dimensões e competências propostas pela BNCC. A boa formação é primordial no processo de ensino e aprendizagem de crianças e jovens, e essa formação tem impactos diretos dentro da sala de aula, contribuindo para melhorar os índices de desenvolvimento da Educação.

O governo investiu na formação de professores da Educação Básica, quando lançou, em 2009, Plano Nacional de Formação de Professores (PARFOR), que visa formar professores que atuam na educação básica e não têm a licenciatura, ou que já possuem uma licenciatura, porém ministram outras disciplinas sem a graduação. O processo se dá da seguinte forma: as Universidades Federais e Institutos Federais oferecem vagas específicas para os professores alvos do programa, fora das vagas que a universidade já oferece no seu sistema normal anual (BRASIL, 2009). “O PARFOR, instituído pelo Decreto $n$. o 6755/2009, que prevê um regime de colaboração entre União, estados e municípios, para a elaboração de um plano estratégico de formação inicial para os professores que atuam nas escolas públicas” (Brasil, 2019). Os cursos são presenciais, exclusivos para professores da rede pública, são gratuitos com financiamento pela Coordenação de Aperfeiçoamento de Pessoal de Ensino Superior (CAPES).

De acordo com a CAPES, os professores que mais procuraram a formação foram da região Norte e Nordeste. De 2099 a 2012, o PARFOR atendeu 28.073 professores da região Norte e 20.781 do Nordeste. Na sequência, aparecem as regiões Sul (3.422 professores), Sudeste (1.847professores) e Centro-Oeste (753 profesores). Esse Plano de governo veio com o intuito de diminuir as desigualdades entre as regiões do país. Antes do lançamento do Plano em 2007, de acordo com o Instituto Nacional de Estudos e Pesquisas Anísio Teixeira (INEP) em todo o Brasil existiam em todo o país 103. 341 professores atuando sem ter pelo menos o ensino médio/magistério (Quadro 1). 
Quadro 1 - Número de Professores da Educação Básica com Escolaridade de Nível Médio (Sem Normal/Magistério) por Localização, segundo a Região Geográfica - 2007.

\begin{tabular}{|c|c|c|c|c|c|c|c|c|}
\hline \multicolumn{9}{|c|}{ EDUCAÇÃO BÁSICA } \\
\hline \multirow{3}{*}{$\begin{array}{c}\text { Região } \\
\text { Geográfica }\end{array}$} & \multicolumn{8}{|c|}{ Professores por Localização } \\
\hline & \multicolumn{2}{|c|}{ Total } & \multicolumn{2}{|c|}{ Somente Urbana } & \multicolumn{2}{|c|}{ Somente Rural } & \multicolumn{2}{|c|}{ Urbana e Rural } \\
\hline & $\mathbf{N}$ & $\%$ & $\mathbf{N}$ & $\%$ & $\mathbf{N}$ & $\%$ & $\mathbf{N}$ & $\%$ \\
\hline Brasil & 103.341 & $100 \%$ & 75.777 & $73,3 \%$ & 25.726 & $24,9 \%$ & 1.838 & $1,8 \%$ \\
\hline Norte & 12.158 & $100 \%$ & 7.417 & $61,0 \%$ & 4.441 & $36,5 \%$ & 300 & $2,5 \%$ \\
\hline Nordeste & 36.677 & $100 \%$ & 21.581 & $58,8 \%$ & 14.550 & $39,7 \%$ & 546 & $1,5 \%$ \\
\hline Sudeste & 33.706 & $100 \%$ & 30.162 & $89,5 \%$ & 3.115 & $9,2 \%$ & 429 & $1,3 \%$ \\
\hline Sul & 12.561 & $100 \%$ & 10.320 & $82,2 \%$ & 1.775 & $14,1 \%$ & 466 & $3,7 \%$ \\
\hline Centro-Oeste & 8.239 & $100 \%$ & 6.297 & $76,4 \%$ & 1.845 & $22,4 \%$ & 97 & $1,2 \%$ \\
\hline
\end{tabular}

Fonte: Adaptado de MEC/Inep/Deed.

Diante desses dados Educacionais, ao profissional da Educação deve-se oferecer também possibilidades de formação continuada para lhe ajudar a assegurar essas dimensões e competências propostas pela BNCC. Como proposta de formação continuada o Governo Federal criou, em 2012, o Pacto Nacional de Alfabetização na Idade Certa (PNAIC) um programa integrado cujo objetivo era a alfabetização em Língua Portuguesa e Matemática, até o $3^{\circ}$ ano do Ensino Fundamental, de todos os alunos das escolas municipais, estaduais, urbanas e rurais brasileiras. Os professores alfabetizadores receberam bolsa de apoio para participar e se dedicar às atividades de formação. Foi um programa de formação continuada presencial aos alfabetizadores que abrangeu todo o Brasil, com parceria entre os municípios e as universidades federais. Porém, teve seu fim no ano de 2018.

Programas dessa natureza são fundamentais na formação do professor frente aos desafios que é o ato de educar, programas como o PNAIC deveriam também abranger toda a educação básica, pois se entende o processo de formação continuada como fundamental no desenvolvimento profissional do professor, deveria ter se tornado uma política de Estado e não apenas de governo.

\section{A NECESSIDADE DE PROFESSORES REFLEXIVOS}

É preciso abandonar o conceito de formação de professores como processos de atualização ou treino, que acontece por meio de aquisição de informações científicas, didáticas e psicopedagógicas, descontextualizado da prática educativa do professor, é necessário para tanto adotar um conceito de formação que consiste em construir conhecimentos e teorias sobre a prática docente, a partir da reflexão crítica. Sobre essa perspetiva, Imbernón (2005) afirma que:

A formação terá como base uma reflexão dos sujeitos sobre sua prática docente, de modo a permitir que examinem suas teorias implícitas, seus esquemas de funcionamento, suas atitudes etc., realizando um processo constante de autoavaliação que oriente seu trabalho. A orientação para esse processo de reflexão exige uma proposta crítica da intervenção educativa, uma análise da prática do ponto de vista dos pressupostos ideológicos e comportamentais subjacentes. (IMBERNÓN, 2005, p. 48-49). 
Assim, o professor como profissional reflexivo que é, não deve atuar como um mero transmissor de conteúdos, mas, com interação com os alunos, professores, e toda a comunidade escolar, sendo capaz de pensar sobre sua prática. Dessa forma, fica evidente a necessidade de adequar as teorias utilizadas em sala de aula com a realidade e a necessidade dos alunos, é preciso que o professor conheça a realidade e o contexto do seu aluno para assim pensar de forma reflexiva sobre sua atuação, e não se basear em teorias que nada têm relação com os aprendizes.

Conforme Alarcão (2005) o professor reflexivo, é um profissional que necessita saber quem é e as razões pelas quais atua, conscientizando-se do lugar que ocupa na sociedade. A autora acrescenta ainda que "os professores têm de serem agentes ativos do seu próprio desenvolvimento e do funcionamento das escolas como organização ao serviço do grande projeto social que é a formação dos educandos" (ALARCÃO, 2005, p. 177).

A reflexão na ação leva em si um saber que está presente nas ações profissionais. O que tem relação com as observações e as reflexões do profissional em relação à forma como ele percorre em sua prática; a descrição consciente dessas ações pode ocasionar mudanças, buscando caminhos para soluções de problemas de aprendizagem. O pensamento crítico sobre sua atuação, assim exercitado, pode levar o profissional a elaborar novas estratégias de atuação, ajustando-se, assim, as situações novas e complexas que vão surgindo dentro de sua atuação profissional. Segundo Zeichner (1993) a:

reflexão também significa o reconhecimento de que a produção de conhecimentos sobre o que é um ensino de qualidade não é prioridade exclusiva das Universidades e centros de investigação e desenvolvimento e de que os professores também têm teorias que podem contribuir para uma base codificada de conhecimentos do ensino (ZEICHNER, 1993, p. 16).

Ainda segundo o autor "A ação reflexiva também é um processo que implica mais do que a busca de soluções lógicas e racionais para os problemas. A reflexão implica intuição emoção e paixão; não é, portanto, nenhum conjunto de técnicas que possa ser empacotado e ensinado aos professores com alguns tentaram fazer" (ZEICHNER, 1993, p. 18). Onde a prática reflexiva não vem com receitas prontas para cada professor, é preciso atuar e pensar sobre sua realidade e problemas reais do seu contexto aonde a comunidade escolar está inserida, cada realidade é diferente da outra, não tem como adotar modelos prontos para problemas diferentes.

Conforme Alarcão (2005), o professor deve ser prático e teórico da sua própria prática. Nesse sentido, "a reflexão sobre o seu ensino é o primeiro passo para quebrar o ato de rotina, possibilitar a análise de opções múltiplas para cada situação e reforçar a sua autonomia face ao pensamento dominante de uma dada realidade" (p. 82-83). Ainda segundo a autora as atitudes reflexivas do professor podem fazer com que os próprios alunos se tornem reflexivos, por meio das propostas de trabalho que lhes forem feitas em aula, do modo como lhes forem apresentadas e em forma de avaliação e reflexão sobre as ações desenvolvidas. Todavia, para que aconteçam melhoras significativas na qualidade do ensino, deve existir uma formação reflexiva dos professores. Atuando de forma reflexiva, estarão 
atuando também de forma dinâmica, assim, tornando-se capazes de construir uma visão crítica sobre suas ações, permitindo-lhes aceitar, adaptar, ou ainda rejeitar ações alheias à realidade de sua sala de aula, acreditando estarem atuando de forma adequada.

Os profissionais da educação não são meros objetos da história, mas sim protagonistas e construtores da sua própria história e do meio em que vivem. A reflexão que não se torna ação política, transformadora da própria prática, não tem sentido no horizonte educativo. Por tanto, é inegável que o pensamento reflexivo contribui, decisivamente, para a promoção do progresso da atuação docente. De acordo com Freire (1996), a reflexão é o movimento realizado entre o fazer e o pensar, entre o pensar e o fazer, ou seja, no "pensar para o fazer" e no "pensar sobre o fazer". Diante disso, a reflexão provém da curiosidade sobre a prática docente, que, transformada em exercício constante, transforma-se em crítica. Contudo, essa reflexão crítica permanente deve constituir-se como orientação própria para a formação continuada dos professores que buscam a transformação por meio de sua prática educativa.

A prática docente crítica, implicante do pensar certo, envolve o movimento dinâmico, dialético, entre o fazer e o pensar sobre o fazer. [...] O que se precisa é possibilitar, que, voltando-se sobre si mesma, através da reflexão sobre a prática, a curiosidade ingênua, percebendo-se como tal, se vá tornando crítica. [...] A prática docente crítica, implicante do pensar certo, envolve o movimento dinâmico, dialético, entre o fazer e o pensar sobre o fazer. (FREIRE, 1996 p. 38).

Para tanto, quando se fala de profissional reflexivo não se está falando propriamente de reflexão sobre conteúdos, a reflexão é própria de cada um e não há um modelo pronto para ser seguido. No entanto, segundo Freire "[...] o importante é que a reflexão seja um instrumento dinamizador entre teoria e prática" (1996, p. 39). Por isso, não basta apenas pensar e refletir, é fundamental que tal reflexão leve o profissional a uma ação transformadora, fazendo-o pensar sobre seus desejos, vontades, histórias.

Assim, destaca-se que para ser reflexivo é preciso refletir não somente sobre a teoria trabalhada, mas sobre a sua prática. Essa reflexão deve ser coletiva com toda a comunidade escolar ao passo que se for isolada pode levar a uma reflexão limitada, o planejamento deve se dar num ambiente colaborativo, facilitando assim o processo de aprendizagem. O professor sozinho tem o pensamento limitado das suas turmas e sala de aula, quando se tem um pensamento coletivo, tem-se não só apenas um professor reflexivo, mas uma escola reflexiva em sua totalidade. Pimenta (2005) ressalta que as escolas que assim atuam, pensando a prática coletivamente, transformam-se em comunidades de aprendizagem nas quais os professores se apoiam e se estimulam mutuamente.

Para que essa reflexão aconteça é preciso também que os cursos de licenciatura como as formações continuadas forneçam essas possibilidades de uma atuação reflexiva do professor. Atualmente, a postura de um professor reflexivo é indispensável frente às dificuldades enfrentadas dentro da sala de aula e da complexidade que se tornou a educação do mundo contemporâneo. Não existe ninguém mais indicado que o professor para analisar criticamente o que está sendo trabalhado em sala de aula, permitindo uma análise crítica entre a teoria e prática, porque, "a diferença entre teoria 
e prática é, antes de mais nada, um desencontro entre a teoria do observador e a do professor, e não um fosso entre teoria e prática" (ZEICHNER, 1993, p. 21).

É importante destacar que não existe atuação profissional docente apenas com os saberes vivenciados na prática contextual, são necessários os saberes teóricos os quais são fundamentais nesse processo. Nesse sentido, Pimenta (2005) destaca a importância da teoria na formação docente, já que “dota os sujeitos de variados pontos de vista para uma ação contextualizada, oferecendo perspectivas de análise para que os professores compreendam os contextos históricos, sociais, culturais, organizacionais, e de si próprios como profissionais" (p. 24), para neles ter uma ação transformadora.

\section{CONSIDERAÇÕES FINAIS}

Ressalta-se assim, a necessidade do empreendimento de políticas de formação para a educação infantil do campo de modo a potencializar a valorização dos professores e o compromisso constante com a Educação de qualidade e transformadora com os povos do campo "capazes de pensar, de articular os saberes na construção de um projeto que viabilize as transformações necessárias às práticas escolares dessa etapa da educação básica.

Para que isso de fato aconteça, deve-se ter investimento público nas escolas, em especial as do campo, não exigindo apenas que o professor faça sua parte sem o auxílio e amparo necessários, mas possibilitando condições para que a escola como um todo se torne um ambiente com as condições necessárias de estrutura física e com profissionais reflexivos e que analisem criticamente a prática pedagógica, sinalizando para uma mudança efetiva da realidade como um todo.

Diante do exposto, acena-se que é imprescindível uma formação sólida e consistente que contemple as reais necessidades dos alunos do campo, em especial na educação infantil, frente à educação para a democracia e cidadania. Entende-se a formação continuada como um processo complexo que não se restringe ao nível de graduação, mas perdura durante toda a vida profissional. Dentro dessa complexidade que é o processo formativo do docente, mostra-se necessário uma formação completa, voltada para as reais necessidades dos docentes que atuam no campo.

É preciso uma educação do campo voltada para ajudar a resolver os problemas sociais onde o cidadão saiba do seu papel diante da sociedade entendendo os problemas globais do mundo e não apenas do lugar em que vive, desenvolvendo assim responsabilidade social e respeito ao próximo.

A investigação constatou a necessidade de uma formação voltada para dar conta da complexidade do conhecimento, das ciências, das relações interpessoais e do desenvolvimento da dimensão cidadã e democrática do indivíduo. Enfim, sustenta-se que a educação e o ensino democrático devem atentar para a realidade do contexto escolar e seu entorno, para que se promova uma cultura mais humana e cidadã, que por sua vez implicará em um processo de formação inicial dos professores voltado para dar conta da complexidade da realidade sócio-educativa. 


\section{REFERÊNCIAS}

ALARCÃO, I. Professores reflexivos em uma escola reflexiva. São Paulo: Cortez, 2005.

ARROYO, M. G. A Educação Básica e o Movimento Social do Campo. In: Por uma educação básica do campo. Petrópolis, RJ: Vozes, 2004.

Arroyo, M. G; CAldart, R. S.; MOlina, M. C (Org). Por Uma Educação do Campo. Petrópolis, RJ: Vozes, 2009.

BRASIL. Lei no 9.394 de 20 de dezembro de 1996. Lei de Diretrizes e Base da educação Nacional. 1996. Disponível: https://bit.ly/3AWN03M. Acesso em: 30 nov. 2019.

BRASIL. Lei no 13.005 de 25 de junho de 2014. 2014. Disponível em: https://bit.ly/2Z1KaO7. Acesso em: 01 jul. 2019

FREIRE, P. Pedagogia da Autonomia: Saberes Necessário à Prática Educativa. São Paulo: Paz e Terra, 1996.

GARCIA, M. C. Formação de Professores. Para uma Mudança Educativa. Porto: Porto, 1999.

GUIMARÃES, V. S. (et al). Políticas Públicas de educação do campo e formação de professores. In XIMENES-ROCHA, S; Colares, M. L I. S (org). Aprendizagem da docência: reflexões sobre os cursos de formação, a inserção profissional e as recentes pesquisas na área. Curitiba: CRV, 2012. p. 45-60

IMBERNÓN, F. Formação Continuada de Professores. Porto Alegre: Artmed, 2010.

IMBERNÓN, F. Formação Docente e Profissional: formar-se para a Mudança e incerteza. 5. ed. São Paulo: Cortez, 2005.

MIZUKAMI, M. G. N, et al.. Escola da Aprendizagem da docência: Processos de investigação e formação. São Carlos: EduFSCar, 2002.

MORIN, E. Os sete saberes necessários à educação do futuro. Tradução de Catarina Eleonora F. da Silva e Jeanne Sawaya. Revisão técnica de Edgard de Assis Carvalho. Brasília: UNESCO, 2000. 
MORIN, E. A cabeça bem-feita: repensar a reforma, reformar o pensamento. 8. ed. Rio de Janeiro: Bertrand Brasil, 2000.

PIMENTA, S. G. (Org.) A formação de Professores na Sociedade do conhecimento. São Paulo: Cortez, 2005.

ROSEMBERG, F., CAMPOS, M.M.; VIANA, C.P. (Org). A formação do educador de creche: sugestões e propostas. São Paulo, FCC/DPE, 1992.

ZEICHNER, K. M. A Formação Reflexiva de Professores, Ideias e Práticas. EDUCA, Lisboa, 1993. Disponível em: https://www.qedu.org.br/. Acesso em: 01 ago. 2019. 